\title{
NEW CRYSTALLINE SILICATES OF POTASSIUM AND SODIUM, THEIR PREPARATION AND GENERAL PROPERTIES.
}

By Ggorge W. MOREY.

Received January 5, 1914:

Of the large and complex group of silicates, those of the alkalies are presumably the easiest to study experimentally, and yet our present knowledge of them is fragmentary. An investigation was accordingly undertaken with the idea of obtaining more definite knowledge of the properties of these compounds, as it is evident that from a study of them it should be possible to obtain information of value in attacking the larger problems relating to the complicated natural silicates. It is the purpose of the present paper to describe methods and apparatus used in the preparation of some new silicates of potassium and sodium, and to point out some of their general properties; their physico-chemical relationships, the investigation of which is now well under way, will be taken up in a later paper.

\section{Historical.}

In discussing the present status of our knowledge of the alkali silicates, it seems unnecessary, in view of the recent excellent summary by Jacoby, ${ }^{1}$ to take up the rather voluminous literature of the subject in extenso. Moreover, we shall consider in this paper only work carried out in the wet way; first, because the new experimental work here recorded deals entirely with the system alkali silicate and water, and secondly, because the other side of the subject has already been discussed by $\mathrm{Niggli}^{2}$ in his paper on the system alkali carbonate and silica.

Up to the present time, no well-defined crystalline silicate of either potassium or sodium has been prepared in the wet way. It is true that several authors have described crystals of hydrated sodium metasilicate obtained from aqueous solution at ordinary temperature, but the observations recorded are not thoroughly concordant. Thus Petersen ${ }^{3}$ describes a monoclinic substance containing 5 molecules of water; Fritsche ${ }^{4}$ describes in detail triclinic crystals containing 6 aq., and also a compound containing 9 aq.; York ${ }^{5}$ reports 7 aq.; several observers have reported 8 aq., including von Ammon, ${ }^{6}$ who describes the monoclinic crystals which he obtained; Jordis ${ }^{7}$ found 6-12 aq.; and Vesterberg ${ }^{8}$ found 9 aq. and, from

' Gmelin-Kraut, "Handbuch der anorganischen Chemie," 7 Auflage, Bd. III, Abt. I, pp. 222-3 and 229-34 (I909).

${ }^{2}$ P. Niggli, This Journal, 35, 1693-I727.

${ }^{3}$ Petersen, Ber., 5, 409-II.

4 Fritsche, Pogg. Ann., 43, I35 (1838).

' York, Trans. Roy. Soc. London, $1857,533-42$.

B von Ammon, Inaug. Diss., Göttingen, I862.

${ }^{7}$ Jordis, $Z$. anorg. Chem., 56, 305 (1907).

${ }^{8}$ Vesterberg, Orig. Comm. VIII Intern. Congr. Appl. Chem., 2, 235-9. 
dehydration experiments, concluded that hydrates containing 3 aq. and 6 aq. also exist. Furthermore, both Jordis and Vesterberg made experiments with sodium silicate solutions containing a great excess of alkaliin one case $I_{4} \mathrm{Na}_{2} \mathrm{O}$ to $\mathrm{I}_{\mathrm{SiO}_{2}}$-but they obtained no crystals richer in alkali than the metasilicate.

From this there seems to be no doubt that $\mathrm{Na}_{2} \mathrm{SiO}_{3}$ forms several crystalline hydrates; none of these, however, have been encountered in the work described in this paper. The question of the composition and range of stability of each of the possible hydrates is still an open one, and can be answered only by an investigation undertaken with this specific purpose in view.

Aqueous Solutions.-The alkali metasilicates, as ordinarily prepared, are largely hydrolyzed, ${ }^{1}$ the silica separating in colloidal form. ${ }^{2}$ It must be emphasized, however, that conclusions in regard to the relative strength of silicic acid, based on the apparent degree of hydrolysis of such solutions, are not necessarily valid; indeed, there is ground for the belief that silicic acid is considerably stronger than has generally been supposed, just as is the case with aluminic acid. ${ }^{3}$ In any case, solubility experiments, such as those made by Vesterberg, ${ }^{4}$ are meaningless, because the phenomenon is one of decomposition. When, for instance, hydrated sodium metasilicate is treated with water, the first infinitesimal portion dissolved is immediately decomposed with the formation of colloidal silica, and the process will go on until some more or less definite end point is attained; but this presumed equilibrium is in no way determined by the real solubility of the sodium silicate itself.

A number of investigators have obtained products containing from two to four, or more, molecules $\mathrm{SiO}_{2}$ to one molecule alkali oxide, but the preparative methods used are, in every case, open to question, and the products were, without exception, amorphous. Most of the methods fall into two classes: (I) precipitation with alcohol, and (2) determination of the ratio alkali oxide: silica in the saturated solution. The first method, by which, e. g., Forchhammer ${ }^{5}$ obtained products of the gross composition $\mathrm{K}_{2} \mathrm{O} .2 \mathrm{SiO}_{2}, \mathrm{~K}_{2} \mathrm{O} .8 \mathrm{SiO}_{2}$, and $\mathrm{Na}_{2} \mathrm{O} .3 \mathrm{SiO}_{2}$, was shown by Ordway ${ }^{6}$ to lead to wholly erroneous conclusions, because the composition of the precipitate depends on the concentration of the solution, the proportion of alkali present, and the amount of alcohol added, and varies

I Loomis, Wied. Ann., 60, 533 (1897); Kahlenberg and Lincoln, J. Phys. Chem., 2, 77 (1898); Kohlrausch, Wied. Ann., 47, 756-64 (1893); Z. physik. Chem., 12, 773 (1893).

${ }^{2}$ Jordis, Z. anorg. Chem., 56, 297 (1907); Mylius, Atti. VI Congr. Intern. Appl. Chem., I, 682 (1907); Kahlenberg and Lincoln, loc. cit.; Kohlrausch, Loc. cit.

${ }^{3}$ Blum, This Journal, 35, I499-I505 (I9I3).

"Vesterberg, loc. cit.

- Forchinammer, Pogg. Ann., 35, 343 (1835).

${ }^{6}$ Ordway, $A m . J . S c i$, [2] 33, 27-36 (1862). 
continually with variation of any of the above factors. That the second method should lead to equally unreliable conclusions is obvious, so that the wide discrepancies between the results of various observers are to be expected. Kohlrausch, ${ }^{1}$ however, from conductivity determinations, concluded that $\mathrm{Na}_{2} \mathrm{O}_{2} \mathrm{SiO}_{2}$ was the richest in $\mathrm{SiO}_{2}$ of any compound of $\mathrm{Na}_{2} \mathrm{O}$ and $\mathrm{SiO}_{2}$ existing in aqueous solution, and that solutions of the metasilicate contain $\mathrm{NaOH}$ and $\mathrm{Na}_{2} \mathrm{Si}_{2} \mathrm{O}_{5}$.

To sum up then: our knowledge of the silicates of sodium and potassium up to the present time has been limited to the facts that these silicates, as they have ordinarily been prepared, dissolve in water, forming solutions which are largely hydrolyzed, and in which most of the silica exists in colloidal condition; and that sodium metasilicate forms one or more crystalline hydrates.

\section{Experimental.}

The experimental work was carried out by the so-called hydrothermal method, the substances being treated in closed bombs with water at high temperatures, and at the consequent high pressures. The apparatus used has been completely satisfactory; its construction is simple, it is easy to manipulate, and it secures absolute freedom from leakover 200 experiments have been made without a single leak - a condition which, combined with the reliability of the temperature determinations, insures the reproducibility ${ }^{2}$ of the results.

Construction of the Bombs.-The construction of the bombs is shown in Fig. I, which is drawn to scale. Each bomb consists essentially of three parts, namely, the body $E$, the plunger $C$, and the screw plug $B$, all made from tool steel. ${ }^{3}$ The body is made from a cylinder 3 inches in diameter

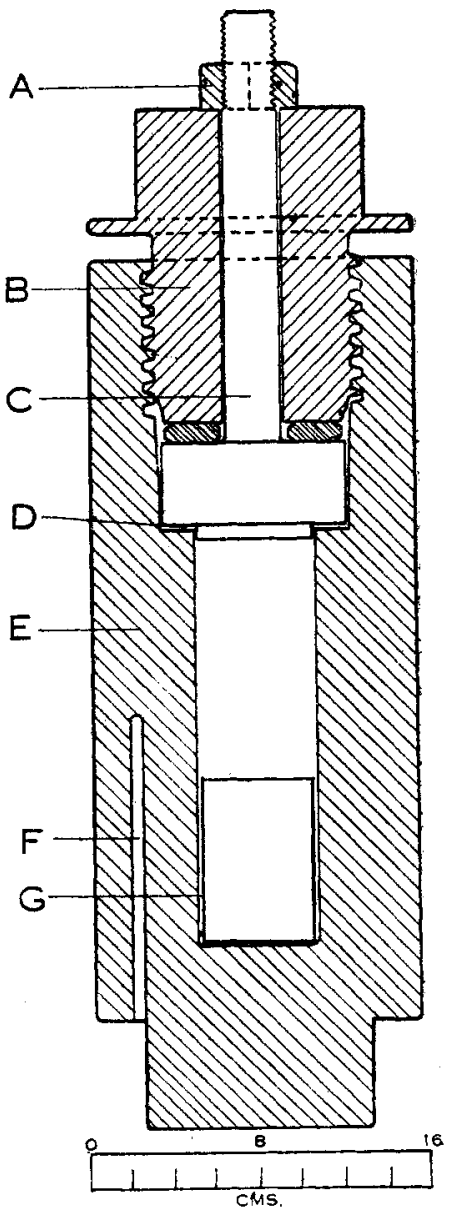

Fig. 1.-Diagram showing the construction of the bomb used. and 8 inches long; by boring out a $I^{1 / 4}$ inch hole to form the chamber;

${ }^{1}$ Loc. cit.

2 The importance of thorough control of the conditions, especially of the degree of filling (the concentration of water in the total space within the bomb) and the temperature, has been demonstrated in a previous paper (Morey and Niggli, ThIs Journal, 35, 1086-II 30 (I9I3).

s Procured from the Halcomb Steel Co., Syracuse, N. Y. 
this hole is enlarged at the top so as to receive the parts by which closure is effected. For about $1 / 4$ inch above the shoulder, at $D$, the hole is cylindrical; above this up to where the screw thread is cut it tapers slightly, so as to allow the plunger to be more easily unseated. Strong threads of the type shown are cut in bomb and plug, the end of each of which is suitably squared off so as to allow one to place the bomb in a vise and screw the plug down hard by means of a wrench. ${ }^{1}$

Between the screw plug and plunger is a steel washer which ensures that the plunger does not rotate while the plug is being screwed down. The lower part of the plunger fits tight into the bomb at $D$; its upper part is a $1 / 2$ inch rod, which passes with a clearance of about $1 / 32$ inch through washer and plug. The projecting portion of this rod is threaded and fitted with the nut $A$; the main purpose of this feature is to aid in unseating the plunger when the bomb is to be opened. There are several advantages in making the head of the bomb as shown, instead of making it in one solid piece. By having the plunger separate and separated from the screw plug by a washer, all turning moment on the copper washed $D$ is eliminated, thus making it easier to obtain a perfectly tight closure. Another important point is, that if experiments are made in which on cooling there may be a residual pressure, one can first unscrew the plug slightly and then, by means of the nut $A$, unseat the plunger, thus, by relieving the pressure while plug and plunger are still securely held by the remaining threads, obviating any chance of accident from this source.

Imprisoned in the annular space between the plunger and the body of the bomb is the flat copper washer $D, 1 / 16$ inch thick, by means of which the joint is made tight. ${ }^{2}$ The washer is always softened by annealing in a flame before use. It is prevented from flowing either upwards or downwards into the chamber of the bomb by the special form given to the plunger, which, as noted above, is made to be a good fit into the bomb just above and below $D$. It is essential that the copper be imprisoned in such a manner, otherwise it will flow at the high temperatures and pressures, thus giving rise to a leak; which in hydrothermal work, as has been pointed out in a previous paper, ${ }^{3}$ cannot be tolerated. As an additional precaution to insure a perfectly tight closure, two knife edges, (not shown in the figure), about $60^{\circ}$ and $1 / 64$ inch high and of slightly different diameters, are turned, one on the shoulder of the bomb, the other on the corresponding portion of the plunger. In order to be able to bring out the washer with the plunger, instead of leaving it within the bomb (in which case its removal is difficult), the lower portion of the plunger,

${ }^{1}$ A wrench 2 feet long suffices.

${ }^{2}$ This type of closure has for some time been successfully employed by Johnston and Adams as a means of holding in very high pressures.

${ }^{3}$ Morey and Niggli, This Journal, 35, I086-1130 (1913). 
which projects into the chamber, is made not exactly cylindrical but is cut inward so as to form a truncated cone of slight angle.

The charge is placed in a crucible $G$ of gold, which rests on the bottom of the bomb. Experience has shown that under such conditions the charge (at least with neutral or alkaline solutions such as we are dealing with here) is not contaminated by the iron of the bomb, so that a lining is unnecessary. Moreover, this method, besides being cheaper and avoiding a difficult piece of construction, facilitates greatly the manipulation, both previous to, and at the close of an experiment; the product is readily accessible and can be quantitatively removed, thus insuring complete freedom from contamination.

Temperature Measurement.-Temperatures are determined by means of a thermoelement inserted in the hole $F, 1 / \mathrm{s}$ inch in diameter, drilled longitudinally in the wall of the bomb, as shown in Fig. I. Elements of copper-constantan are generally employed; the electromotive force is measured on a direct reading galvanometer, whence, with the aid of an appropriate calibration curve, the temperatures are derived. In view of the massive construction of the bomb and enclosing furnace and of the mode and duration of an experiment, it seems probable that the temperature throughout the chamber is fairly uniform and that it is indicated satisfactorily by the thermoelement junction in the top of the hole $F$. Indeed, experiments have shown that there is no appreciable temperature differences at different levels within the thermoelement hole. The temperatures given are, therefore, accurate to $\pm 5^{\circ}$ or better, an accuracy which is ample for the purpose in hand; moreover, what uncertainty there is can easily be reduced to $\pm \mathrm{I}^{\circ}$ as soon as the occasion demands it.

Construction of the Furnaces.-The construction of the electrical resistance furnaces used is shown in Fig. II, which is drawn to scale. The resistance wire, of "trichrome," is wound on an iron pipe, $D$, from which it is insulated by three layers of mica composition, such as is used in electrical work. The size and amount of wire are different in different furnaces: one is wound with No. 18 wire to give $300^{\circ}$ when placed directly on a 55 volt line, and takes 5.6 amperes to hold it at that temperature; another is wound with No. 16 wire to give $500^{\circ}$ when placed directly on a I Io volt line, and takes 5.8 amperes to hold it at that temperature; the other two are wound with No. I 6 wire and are used with outside resistance, thus enabling one to secure intermediate temperatures.

The thermal insulation of the furnace consists of loose magnesia, $E$, held in place by the sheet-iron shell $F$, and the asbestos end-pieces $C$; the latter are held in place by the annular iron end-pieces, $B$, which fit tightly on to a slight shoulder cut on either end of the iron pipe $D$. The whole furnace is mounted in a strap iron frame, $G$, fastened by screws to the annular end-pieces $B$. The frame is provided with trunnions, $I$, 
which are mounted on suitable bearings in a support (not shown in the figure); by this means the furnace may be rotated about a horizontal axis or inclined at any angle. This style of furnace is easy to construct and simple in operation; in case a heating element is burned out the furnace
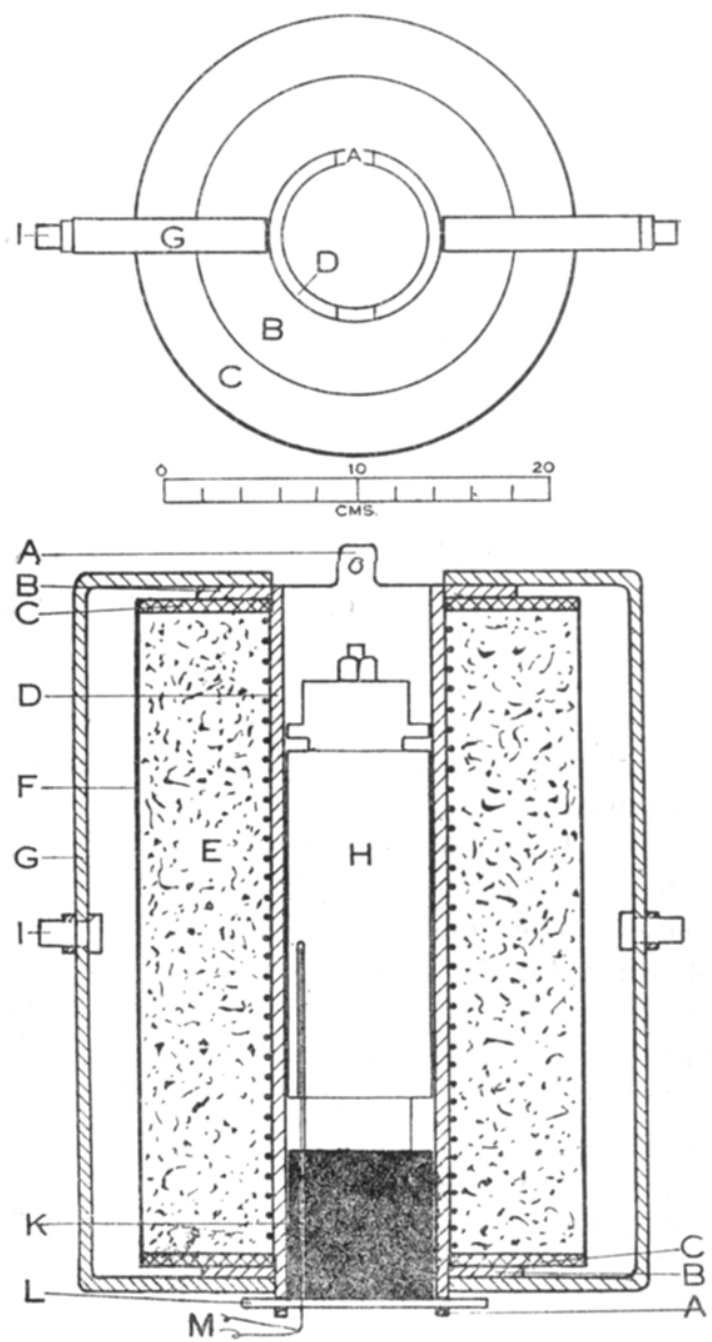

Fig. 2.-Diagram showing the construction of the furnace used. can be dismantled, the element replaced, and the furnace re-assembled in a short time.

The bomb $H$ (shown in outline in Fig. 2) rests on a graphite plug, $K$, which is held in place by the rod $L$, passing through holes in the ears $A A$ projecting from the main portion of the pipe $D$. A similar plug (omitted from the figure for the sake of clearness) fills the upper end of the tube. The thermoelement $M$ passes through a hole in the bottom plug, as shown.

Materials Used. - The solid substances used in almost all the work consisted of finely pulverized glasses, which had been made by fusing mixtures of quartz and alkali carbonate in different proportions. The same components were also introduced into the bomb in other forms: the alkali as chloride, carbonate, hydroxide, and as silicate glass; the silica as quartz and as an amorphous precipitate; but these variations were altogether without influence on the resultant product. Since this is so, it is best to use the (anhydrous) glasses prepared as above described, not only because the components are intimately mixed and in a soluble 
and reactive form, but also because their use avoids any possible complications due to the introduction of other components.

Mode of Experiment.-A quantity of the alkali-silica mixture is weighed out into the gold crucible, a weighed amount of water is added and the crucible placed in the bomb, which is then closed and set in a furnace heated to the desired temperature. After being held at that temperature for a certain time, usually 20 hours, the bomb is cooled suddenly by plunging into water, opened and the crucible transferred to a desiccator; the entire operation can be completed within five minutes after withdrawal of the bomb from the furnace. The products are examined microscopically and chemically; crystals, if present, are, when possible, removed and analyzed.

Attention is directed to the following details of manipulation: All bearing surfaces on the washer and plug, the threads especially, must be well lubricated with a mixture of graphite and oil; the graphite by forming a coating on the steel surfaces prevents their sticking or welding together, as they will do if not lubricated. When a bomb is heated to a high temperature, e. g., $500^{\circ}$, there may be sufficient difference in expansion between the steel and the copper so that the joint ceases to hold tight when the bomb is cooled down again, consequently in such a case care must be taken in the cooling of the bomb that the joint is always above the surface of the water; otherwise a little water may creep in during the cooling.

We shall now, after a few words on the analytical methods employed, describe the new crystalline products, and proceed to a discussion of the behavior of the hydrous alkali silicate glasses obtained in the course of thework.

Analytical Methods.--The analytical methods used in the course of the following work were simple. Water was determined by heating in an electric furnace at $800^{\circ}$; alkalies were weighed as chlorides, silica as $\mathrm{SiO}_{2}$. The samples were decomposed by evaporating with $\mathrm{HCl}$, three evaporations with intervening filtration being necessary for complete separation of alkali chloride and silica. The latter was always tested by evaporation with HF; all operations were carried out in platinum vessels. When but a small amount of material was available, as was the case in the analysis of the $\mathrm{K}_{2} \mathrm{Si}_{2} \mathrm{O}_{5}$ crystals, the procedure was simplified. In this case it was necessary only to heat as above for the determination of $\mathrm{H}_{2} \mathrm{O}$, to evaporate twice with $\mathrm{HF}$, followed by double evaporation with $\mathrm{HCl}$ to convert the fluorides to chlorides; since the only components present. are water, alkali oxide, and silica, it is perfectly admissible to calculate the latter from the loss in weight.

\section{Crystalline Products.}

Potassium Hydrogen Disilicate. $\mathrm{K}_{2} \mathrm{O} . \mathrm{H}_{2} \mathrm{O} .4 \mathrm{SiO}_{2}$, or $\mathrm{KHSi}_{2} \mathrm{O}_{5}$. - When an anhydrous potassium silicate glass is heated with water, the product. 
obtained depends on the temperature, amount of water present (pressure), and concentration-ratio alkali oxide/silica in the sample of glass. If, for example, 2 grams of a glass of the composition $\mathrm{K}_{2} \mathrm{O} .2 \mathrm{SiO}_{2}$ is heated with 2 grams $\mathrm{H}_{2} \mathrm{O}^{1}$ at $400^{\circ}$, the product is a clear, hard, homogeneous, hydrous glass. If, however, the amount of water is reduced to less than I gram, the product is a mixture of hydrous glass and crystals. The crystals obtained under these conditions can be freed from adhering glass by leaching with hot water without affecting the sharpness of the crystal angles. The same crystals have been repeatedly obtained under a wide range of experimental conditions; at temperatures ranging from $200-45^{\circ}$, from glasses ranging in composition ratio from $\mathrm{K}_{2} \mathrm{O} / \mathrm{SiO}_{2}$ to $\mathrm{K}_{2} \mathrm{O} / 5 \mathrm{SiO}_{2}$, also when the original components were potassium carbonate and silica. Analysis of the crystals, in which each component was determined directly, yielded the following results:

$\begin{array}{llcc}\mathrm{K}_{2} \mathrm{O} . & \mathrm{H}_{2} \mathrm{O} & \mathrm{SiO}_{2} \\ \text { Found } \ldots \ldots \ldots \ldots \ldots \ldots & 26.71 \% & 5 . \mathrm{II} \% & 68.16 \% \\ \mathrm{~K}_{2} \mathrm{O} . \mathrm{H}_{2} \mathrm{O} .4 \mathrm{SiO} \text { requires..... } & 26.65 \% & 5.10 \% & 68.25 \%\end{array}$

The crystals then have the composition $\mathrm{K}_{2} \mathrm{O} \cdot \mathrm{H}_{2} \mathrm{O} \cdot 4 \mathrm{SiO}_{2}$, and are, therefore, by analogy with the compounds to be described later, considered to be potassium hydrogen disilicate, $\mathrm{KHSi}_{2} \mathrm{O}_{5}$. This compound crystallizes readily in orthorhombic crystals, ${ }^{2}$ the density of which is $2.417=0.002,{ }^{3}$ at room temperature, referred to water at $4^{\circ}$. The crystals are not readily affected by water, even by treatment at $100^{\circ}$ for several hours; when heated with dilute hydrochloric acid they are decomposed, leaving a birefringent residue containing only silica and water. ${ }^{4}$ The vapor pressure of the water in the crystals is very slight; they can be heated in air to $35^{\circ}$ without losing in weight, but the loss becomes appreciable at $45^{\circ}$.

Potassium Disilicate, $\mathrm{K}_{2} \mathrm{O} .2 \mathrm{SiO}_{2}$ or $\mathrm{K}_{2} \mathrm{Si}_{2} \mathrm{O}_{5}$. - When anhydrous potassium silicate glass of the composition ratio $\mathrm{K}_{2} \mathrm{O} / 2 \mathrm{SiO}_{2}$ is heated at about $450^{\circ}$, with an amount of water insufficient to give complete solution, crystals are formed the optical properties of which, so far as determinable, are identical with those of the compound $\mathrm{K}_{2} \mathrm{O} .2 \mathrm{SiO}_{2}$ found by Niggli. ${ }^{5}$ "These crystals, unlike those of $\mathrm{KHSi}_{2} \mathrm{O}_{5}$, break down immediately in water, and absorb moisture very rapidly from the air. On this account it has proved impracticable to separate the crystals from adhering glass sufficiently well to provide satisfactory material for analysis, or to make

1 The data given refer, of course, to a bomb of the capacity (about $75 \mathrm{cc}$.) given above.

See crystallographic description by C. N. Fenner, postea.

3 Determined for me by $\mathrm{H}, \mathrm{E}$. Merwin by the method described in $A m$. J. Sci., 32, $425^{-28}(\mathrm{~L} 91 \mathrm{I})$.

Ci. Rinne, Neues Jahrb. Min. Geol., I, 139-48 (1896). This question is being anvestigated further.

5 Niggli, This Journal, 35, r694-1727 (1913). 
measurements on the goniometer. In one case, however, the crystals were so large that they could be separated from most of the hydrous glass by careful selection; the product was still contaminated by a small amount of hydrous glass, and weighed only 0.0717 gram. Analysis of this material yielded the following results:

\begin{tabular}{|c|c|c|}
\hline & Per cent. by wt. & Mol. ratio \\
\hline $\mathrm{K}_{2} \mathrm{O}$. & $\ldots 39.5$ & 1.000 \\
\hline $\mathrm{SiO}_{2}$ (by diff.) & 47.9 & I. 894 \\
\hline $\mathrm{H}_{2} \mathrm{O} \ldots \ldots \ldots$ & $\ldots 2.6$ & $\ldots$ \\
\hline
\end{tabular}

The composition ratio of the original anhydrous glass in this experiment was I : 1 , while that of the crystals is evidently close to $r: 2$; some amount of water and a slight excess of $\mathrm{K}_{2} \mathrm{O}$ are to be expected from the circumstance that the crystals could not be entirely freed from hydrous glass. This analysis is not absolutely conclusive, but the correctness of the formula $\mathrm{K}_{2} \mathrm{O} .2 \mathrm{SiO}_{2}$ is further demonstrated by two distinct lines of argument. First, this product, obtained from hydrotus solutions in the neighborhood of $500^{\circ}$, is identical with the product obtained from dry melts in the neighborhood of $1000^{\circ}$ by Niggli. Second, evidence obtained in the course of an extensive series of experiments on the temperature-pressure-solubility relations in the system $\mathrm{K}_{2} \mathrm{O}: \mathrm{SiO}_{2}: \mathrm{H}_{2} \mathrm{O}$ points to the formation of this compound; this evidence will be presented in a later paper. The range within which this compound is stable is now being investigated; present experience indicates, in general, that at higher temperatures it is more stable than $\mathrm{KHSi}_{2} \mathrm{O}_{5}$, and that excess of potash is more favorable to its stability at lower temperatures than is excess of silica.

Sodium Disilicate, $\mathrm{Na}_{2} \mathrm{O}_{2} \mathrm{SiO}_{2}$, or $\mathrm{Na}_{2} \mathrm{Si}_{2} \mathrm{O}_{5}$. - When anhydrous glasses composed of $\mathrm{Na}_{2} \mathrm{O}$ and $\mathrm{SiO}_{2}$ are used in place of potassium silicate glasses, the products obtained are quite different. When a glass of the composition ratio $\mathrm{Na}_{2} \mathrm{O} / \mathrm{SiO}_{2}$ is heated with considerable water above $400^{\circ}$, a homogeneous glass can be obtained, as in the potassium system, though the sodium systems have a considerably smaller solubility than the corresponding potassium systems.

When, however, a glass of the above composition ratio is heated at $300^{\circ}$ with an amount of water insufficient to give complete solution, crystals are obtained which, in optical properties, ${ }^{1}$ resemble $\mathrm{KHSi}_{2} \mathrm{O}_{5}$ and $\mathrm{K}_{2} \mathrm{Si}_{2} \mathrm{O}_{5}$ and which resemble the former compound also in that they can be purified by leaching with water; but on prolonged contact with cold water they are decomposed, leaving a residue of hydrous silica. An analysis in which each component was determined directly, made with a sample of selected crystals of this compound, weighing 0.1701 gram, yielded the following results:

${ }^{1}$ See crystallographic description by Fenner, postea. 


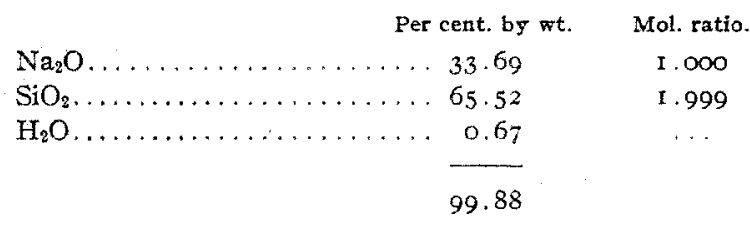

This compound is, then, sodium disilicate, $\mathrm{Na}_{2} \mathrm{Si}_{2} \mathrm{O}_{5}$, analogous to the above potassium salts. It was also obtained at higher temperatures when using glasses whose composition ratio $\mathrm{Na}_{2} \mathrm{O} / \mathrm{SiO}_{2}$ was less than unity.

Sodium Metasilicate, $\mathrm{Na}_{2} \mathrm{O} . \mathrm{SiO}_{2}$, or $\mathrm{Na}_{2} \mathrm{SiO}_{3}$. $-\mathrm{A}$ second crystalline compound formed in the system $\mathrm{Na}_{2} \mathrm{O}: \mathrm{SiO}_{2}: \mathrm{H}_{2} \mathrm{O}$ is the metasilicate, $\mathrm{Na}_{2} \mathrm{SiO}_{3}$. When a glass of the composition ratio $\mathrm{Na}_{2} \mathrm{O} / \mathrm{SiO}_{2}$ is heated with water at temperatures above $400^{\circ}$, crystals are formed whose isolation is difficult because they are decomposed very rapidly by water. Because of this circumstance the separation of pure unattacked crystals was not possible, but that they are anhydrous sodium metasilicate follows from several distinct lines of argument. First, when a glass of the composition ratio $\mathrm{Na}_{2} \mathrm{O} / \mathrm{SiO}_{2}$ is heated at $500^{\circ}$ with but a small amount of water, the product is wholly crystalline and practically anhydrous. Second, in some experiments in which more water was used, masses of crystals were obtained, together with a thick viscous solution. The crystals were freed as well as possible from the very viscous solution by pressing between filter paper; yet under the microscope they still showed a thin coating of solution. Analysis of a sample of these crystals weighing 0.1397 gram yielded the following results:

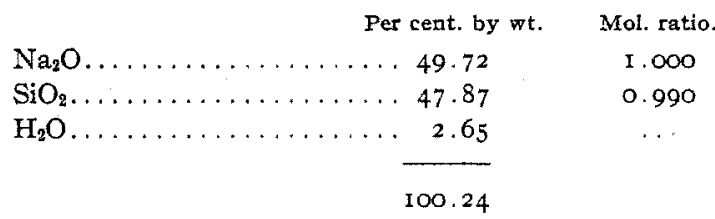

The crystals are evidently anhydrous sodium metasilicate; the small amount of water present, and the slight deficiency in silica, are to be ascribed to the presence of the small amount of viscous solution mentioned above. Third, the optical properties of these crystals separating from aqueous solution at about $500^{\circ}$ appear to be identical with those of the crystals of anhydrous sodium metasilicate obtained from dry melts by Niggli.

The "Sohubility" of the Alkali Silicates-As we have noted above, $\mathrm{KHSi}_{2} \mathrm{O}_{5}$ and $\mathrm{Na}_{2} \mathrm{Si}_{2} \mathrm{O}_{5}$ are not readily affected by water, while $\mathrm{K}_{2} \mathrm{Si}_{2} \mathrm{O}_{5}$ and $\mathrm{Na}_{2} \mathrm{SiO}_{3}$ are decomposed very rapidly. But from these facts one can draw no necessarily valid conclusions as to their real solubility, $i$. $e$., as to the equilibrium between a solid of definite composition and the same 
substance in a solution saturated with it. The process is one of decomposition, the rate of which differs from one to another of the above four substances; it may be that the real solubility is roughly parallel to the rate of decomposition, especially when the latter is small, but this kind of reasoning must be employed with caution. This topic will be reverted to when the equilibrium relations at high temperatures shall have been more definitely ascertained.

General Remarks.-Attempts to prepare the compound $\mathrm{NaHSi}_{2} \mathrm{O}_{5}$, analogous to $\mathrm{KHSi}_{2} \mathrm{O}_{5}$, were unsuccessful, as were also all efforts to obtain crystals of $\mathrm{K}_{2} \mathrm{SiO}_{3}$. In this connection it is interesting to note that $\mathrm{Niggli}{ }^{1}$ found that at higher temperatures in the systems $\mathrm{K}_{2} \mathrm{O}-\mathrm{SiO}_{2}-\mathrm{CO}_{2}$ and $\mathrm{Na}_{2} \mathrm{O}-\mathrm{SiO}_{2}-\mathrm{CO}_{2}$, the stable alkali silicates are; in the potash system, $\mathrm{K}_{2} \mathrm{Si}_{2} \mathrm{O}_{5}$ and $\mathrm{K}_{2} \mathrm{SiO}_{3}$; in the soda system, $\mathrm{Na}_{2} \mathrm{SiO}_{3}$ and $\mathrm{Na}_{4} \mathrm{SiO}_{4}$; increase in temperature in both cases favors the second form. This is in complete harmony with the hydrothermal results; in the potash system at the lower temperatures $\mathrm{KHSi}_{2} \mathrm{O}_{5}$ is stable and increase of temperature favors first $\mathrm{K}_{2} \mathrm{Si}_{2} \mathrm{O}_{5}$, then (presumably) ${ }^{2} \mathrm{~K}_{2} \mathrm{SiO}_{3}$; in the soda system at lower temperatures $\mathrm{Na}_{2} \mathrm{Si}_{2} \mathrm{O}_{5}$ is stable, and increase of temperature favors first $\mathrm{Na}_{2} \mathrm{SiO}_{3}$, then (presumably) ${ }^{2} \mathrm{Na}_{4} \mathrm{SiO}_{4}$.

Remarks on the Disilicates. -The ease with which the disilicates of sodium and potassium can be formed hydrothermally is in striking contrast to the rarity of the occurrence of minerals which can, with any degree of certainty, be considered essentially as disilicates, that is, as salts of the hypothetical acid $\mathrm{H}_{2} \mathrm{Si}_{2} \mathrm{O}_{5}$. The only mineral that is unquestionably a disilicate is rivaite, $\left(\mathrm{Ca}, \mathrm{Na}_{2}\right) \mathrm{Si}_{2} \mathrm{O}_{5}$, described recently by Zambonini, ${ }^{3}$ which occurs very sparingly among the ejected blocks at Vesuvius. The hydrous minerals okenite and apophyllite furnish a ratio of $\mathrm{CaO} / \mathrm{SiO}_{2}$ which is that of a disilicate, the composition of the latter being somewhat complicated by the presence of potassium and of more or less fluorine. Both of these may possibly be regarded as hydrated disilicates. In the text-books the very rare petalite, $\mathrm{LiAl}\left(\mathrm{Si}_{2} \mathrm{O}_{5}\right)_{2}$ and milarite, $\mathrm{HKCa}_{2} \mathrm{Al}_{2}$ $\left(\mathrm{Si}_{2} \mathrm{O}_{5}\right)_{6}$ are cited as disilicates, as are the zeolites ptilalite and mordenite, if we accept Clarke's interpretation of their constitution. All of these, however, contain alumina, and there is at present no assurance that it would not be equally rational to regard them as derivatives of aluminosilicic acids.

\section{Non-crystalline Products.}

Preparation of Solid and Pasty Glasses.-When alkali silicate glass is heated with water, the product obtained depends on the temperature, composition ratio alkali oxide/silica in the original glass, and concentra-

1 P. Niggli, This JournaL, 35, r693-1727 (1913).

2 Inferred from analogy with the results obtained by Niggli.

3 F. Zambonini, Atti accad. Sci, Nap., 12, No. I2, I6 (1912). 
tion of the water (pressure). "The quantitative relations of these factors have not yet been ascertained, but a number of interesting qualitative observations have been made. When, for example, about 2 grams of an anhydrous glass of the composition ratio $\mathrm{K}_{2} \mathrm{O} / 2 \mathrm{SiO}_{2}$ is heated with from $I-5 \mathrm{cc}$, water, the cooled product is a hard homogeneous glass containing considerable water (from 8 to $25 \%$ ), the amount depending on the temperature and initial concentration ratios of the components. As the amount of water present is increased, the amount in the glass increases, in general accord with Henry's law. As the water content of the glass increases above $25 \%$, the product passes gradually, and continuously, from a hard, brittle glass to a very stiff paste and finally to a very viscous. solution resembling ordinary water glass. This is a striking illustration: of the fact that a glass is merely a supercooled liquid.

That the hard glasses were liquid at the temperature of the experiments was proved in a number of ways. One way was to tip the bomb to one side, to an angle of about $15^{\circ}$, while heating, and to the other side while cooling; the glass was found to be collected on the side of the crucible which was lower during the cooling. When the concentration of the water was reduced to such an extent that some crystals were formed, they remained on the side of the crucible that was lower during the heating, while the solution in contact with them flowed away and froze solid on the side that was lower during the cooling.

It is, therefore, established conclusively that liquid solutions, containing water and alkali silicate, may exist in equilibrium with solid and vapor at temperatures up to $500^{\circ}$. It should also be pointed out that these hydrous glasses, liquid at the temperature of the experiment, may be regarded as fused mixtures, the melting point of the alkali silicate having been greatly lowered by the addition of water. For example, $\mathrm{K}_{2} \mathrm{Si}_{2} \mathrm{O}_{5}$ melts at about 1 IOI 5 , but addition of about $8 \%$ of $\mathrm{H}_{2} \mathrm{O}^{1}$ lowers its melting point to about $500^{\circ}$. It is probable that the system alkali silicate and water belongs to the type in which the solubility curve is not intersected by the critical curve; ${ }^{2}$ but discussion of this phase of the problem is postponed until quantitative experimental results can be presented in detail.

Preparation of Pumiceous Glasses.-The glasses just described were obtained under the previously mentioned experimental conditions, that is, the gold crucible containing the charge was placed in the bottom of the chamber of the bomb, and cooling was effected by plunging the bomb suddenly into cold water, bottom first; under these conditions rapid cooling

It is evident that the system will be at the pressure corresponding to the vapor pressure of the solution; reduction of pressure at constant temperature will result ultimately in solid and vapor.

${ }^{2} \mathrm{Cf}$. Morey and Niggli, Thrs Journal, 35, I086-1130 (I913), and the papers by Smits and by Niggli, referred to therein. 
results, with the charge cooling as rapidly as, or more rapidly than, the vapor phase above. If, on the other hand, the crucible is supported near the top of the chamber, in such a manner (e.g., on a porcelain tube) that its heat is conducted away less rapidly, the phenomena are very different. In this case the wall and vapor space are cooled more rapidly than the water-containing mixture in the crucible; consequently rapid diminution of the total pressure sets in, as a result of which the water in the liquid mixture suddenly expands, carrying with it, and at the same time freezing, the non-volatile portion of the charge. This produces a light, porous pumice of nearly anhydrous material. In other words, when the solution is cooled without release of pressure the product is a clear, homogeneous glass; when the total pressure in the bomb is suddenly diminished, the outburst of vapor causes the formation of pumiceous material.

Behavior of the Hydrous Glasses when Heated in Air.-A noteworthy property of the clear, homogeneous, hydrous glasses is exhibited when they are heated in air. If a fragment of this glass the size of a pea is placed in a $30 \mathrm{cc}$. crucible and heated over a flame, the substance swells enormously, often overflowing the crucible, ${ }^{1}$ the swelling continuing until most of the water has been driven off. The resulting sponge, the general appearance of which is similar to that of the pumiceous glasses described above, is composed of vesicles of alkali silicate glass, often with walls thin enough to show interference colors.

\section{Crystallographic and Optical Properties.} BY C. N. FanNer.

Potassium Hydrogen Disilicate, $\mathrm{KHSi}_{2} \mathrm{O}_{5}$. - The crystals obtained were generally of fair size and in one instance sufficiently large for goniometric measurements; crystal outlines well developed. The habit of the crystals used for goniometric work is shown in Fig. 3. Measurements gave the following results: $001 \wedge 100,90^{\circ} 0^{\prime} ; 100 \wedge$ I $10,52^{\circ} 32^{\prime} ;$ I IO $\wedge \overline{1} 10$, $74^{\circ} 56^{\prime}$. In other preparations additional faces were sometimes present, especially macro- and brachy-domes (ror and or I), but in such cases the crystals were too minute for goniometric manipulation. Measurement with the microscope gave for IOO $\wedge$ IOI, $60^{\circ}-62^{\circ}$.

The habit of the crystals varied considerably. Commonly they were elongated parallel to the vertical axis, but it was not unusual for them to show tabular flattening parallel to oor or to roo. Cleavage was well-developed parallel to front and side pinacoids.

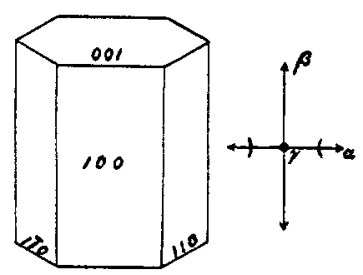

Fig. 3.- $\mathrm{KHSi}_{2} \mathrm{O}_{5}$.

The optical orientation is shown in Fig. 3. As indicated, the crystals

${ }^{1}$ Barus, $A m$. J. Sci., [4] 9, I6I-75 (I900), has described a similar phenomenon, which doubtless is to be explained in the same way. 
are biaxial, positive. The refractive indices, as determined by the immersion method, vary somewhat in different preparations, perhaps owing to a slight solvent action of water in abstracting $\mathrm{K}_{2} \mathrm{O} ; \alpha=\mathrm{I} .480-\mathrm{I} .495$, $\beta=1.530-1.535$; the higher values are probably more nearly correct. Average of a number of determinations of optic axial angle give for $2 \mathrm{E}$ $69^{1 / 2}{ }^{\circ}$. The crystals are evidently orthorhombic.

Friedel and Sarasin, ${ }^{1}$ in hydrothermal experiments, obtained a hydrated silicate of potassium, whose crystallographic properties agree closely with the above.

Potassium Disilicate, $\mathrm{K}_{2} \mathrm{Si}_{2} \mathrm{O}_{5}$. - The crystals of this compound are difficult to work with, as they deliquesce rapidly and also enter into reaction with the immersion liquids. Some of their properties have been described in connection with a previous investigation by $P$. Niggli. ${ }^{2}$ The crystals obtained in the present investigation were rather larger, and at times were free from any adherent material, such as glass. It was possible, therefore, to obtain additional information. In a number of preparations the crystals were sufficiently large for goniometric work, but their hygroscopic character prevented such determinations being made. Measurements were, therefore, confined to those which could be made with the microscope.

The crystals showed tabular habit, and under a binocular appeared as pearly scales, similar to Fig. 4. The cleavage parallel to the flat face is micaceous. There is also a strong cleavage parallel to the axis $\gamma$ and another less well developed parallel to $\beta$. Frequently, contact

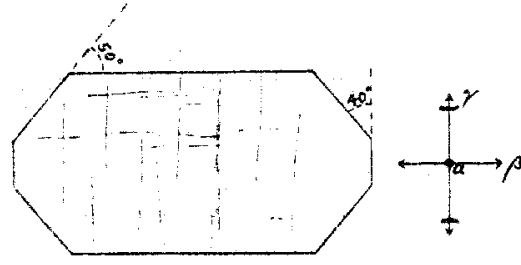

Fig. 4. $-\mathrm{K}_{2} \mathrm{Si}_{2} \mathrm{O}_{3}$ with the index liquid develops a reticulated effect approximately parallel to $\alpha$. The crystal faces bounding the plates are shown in Fig. 4, but the predominance of one or another set of faces varies among different crystals, so that the outline may become quite different. Frequently they are lozenge-shaped. The crystals lying upon the flat face show the emergence of an acute negative bisectrix. Axial angle is rather large (just beyond limits of field of an objective having numerical aperture of 0.95). Indices of refraction are a little uncertain because of reactions with the immersion liquids, but $\beta$ is very close to 1.500 . The crystals are apparently orthorhombic.

Sodium Disilicate, $\mathrm{Na}_{2} \mathrm{Si}_{2} \mathrm{O}_{5}$.-Usually in scaly crystals, of form shown in Fig. 5; very pearly lustre on face I00; cleavage micaceous parallel to IOO, good parallel to axis $\gamma$. A number of crystals were measured on

1 Friedel and Sarasin, Bull. soc. min., 4, 171 (188r).

2 P. Niggii, Thrs Jotrnal, 35, 1693 (1913). 
goniometer, but signals were multiple or indistinct, and results are only approximate. Values obtained were: I IO $\wedge \overline{\mathrm{I}} \mathrm{IO}=3 \mathrm{I}^{1} / 2^{\circ}$; oI $\mathrm{I} \wedge \mathrm{O} \overline{\mathrm{I}} \mathrm{I}=60^{\circ}$. Habit sometimes elongated as shown, sometimes as nearly regular hexagons. Parallel extinction; negative optical character. Average of a number of measurements of optic axial angle gave $2 \mathrm{E}=105^{\circ}$. Indices of refraction $\alpha=1.500, \beta=\mathrm{I} .5 \mathrm{IO}$, $\gamma=\mathrm{I} .5 \mathrm{I} 5$.

Sodium Metasilicate, $\mathrm{NaSi}_{2} \mathrm{O}_{3}$.-These crystals rarely showed good crystal outline. They were usually more or less acicular, with fibrous cleavage parallel to elongation. These forms showed parallel extinction,

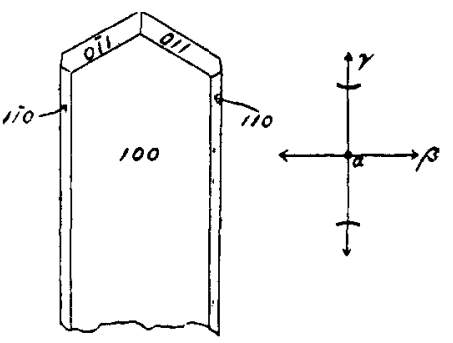

Fig. 5. $-\mathrm{Na}_{8} \mathrm{Si}_{2} \mathrm{O}_{5}$. and elongation was always $\gamma ; \alpha$ was perpendicular to elongation. To judge from the manner in which the brushes of the optic figure disappeared upon rotation of the stage, $\gamma$ is the acute bisectrix and the crystals may be uniaxial. As the compound is soluble in water the crystals could not be isolated from the pasty glass in which they were imbedded. The mean index of refraction was about 1.5 IO. In one preparation wellformed individual crystals appeared, which were believed to be the same compound, though this is not quite certain. These were perfect hexagonal prisms, terminated by pyramids. The crystals lay upon their sides and gave an optic figure perpendicular to one of the axes of elasticity. The brushes always disappeared in the direction of elongation, which was $\gamma$. The same sort of figure was obtained when the crystals were rolled over in the thick mother liquor so as to rest upon another side, so that the mineral was probably uniaxial, positive. The interior angle of the terminating pyramid of these crystals was about $126^{\circ} .1$

\section{Summary.}

Hitherto, no well-defined crystalline silicates of potassium or sodium have been known. Several hydrated forms of sodium metasilicate have been described, but require further investigation, since their composition and range of stability are uncertain. None of these hydrated forms appeared in the course of the present investigation, which deals with the relations of the silicates of potassium and sodium with water at high temperatures and at the consequent high pressures.

In the investigation of such hydrous systems at high temperatures, reproducible results can be attained only if the conditions of experiment are carefully defined and controlled; in especial the concentration (pressure) of the water must be definite--in other words, leaks cannot be tolerated. The apparatus and methods described in the foregoing pages fulfil

${ }_{1}$ Compare crystals of $\mathrm{Na}_{3} \mathrm{SiO}_{3}$ obtained from fusion by P. Niggli, This JourNaI, 35, 1693 (1913). 
the various requirements admirably; in a series of over 200 experiments no sign of leak has been observed.

Four new crystalline alkali silicates-namely, $\mathrm{K}_{2} \mathrm{Si}_{2} \mathrm{O}_{5}, \mathrm{KHSi}_{2} \mathrm{O}_{5}, \mathrm{Na}_{2} \mathrm{Si}_{2} \mathrm{O}_{5}$ and $\mathrm{Na}_{2} \mathrm{SiO}_{3}-$-have been prepared. Of these the first three are derivatives of disilicic acid; they all form orthorhombic crystals, but differ markedly in their behavior toward water. $\mathrm{K}_{2} \mathrm{Si}_{2} \mathrm{O}_{5}$ is quickly attacked by water, $\mathrm{Na}_{2} \mathrm{Si}_{2} \mathrm{O}_{5}$ less readily, while $\mathrm{KHSi}_{2} \mathrm{O}_{5}$ may be left in contact with water, even for some hours at $100^{\circ}$, without appreciable decomposition. The fourth compound is anhydrous sodium metasilicate, which is readily attacked by water; this compound has been known heretofore only as a somewhat indefinite hydrate.

In addition to the crystalline products, a series of hydrous glasses was obtained. These glasses are merely supercooled liquids, each of which represents the composition of a solution unsaturated under the conditions of experiment. They are perfectly hard, even though they contain up to $25 \%$ water; when heated in the air they lose their water, swelling up in the process in a sponge-like structure often with extremely thin vesicular walls.

\footnotetext{
Ggophysical, Laboratory.

CARNEGIF INSTITUTION OF WASHINGTON,
} WASHINGTON, D. C

\section{RECENT WORK IN INORGANIC CHEMISTRY.}

By Jas. LewtS Howe.

Received December 2, 1913.

While the past twelve months have witnessed no startling developments in the field of inorganic chemistry, there has been no diminution in volume of work. Perhaps the two strongest tendencies are (I) to go over old work with modern methods and in the light of modern theories, with resulting confirmation or otherwise, and (2) to project new theories into wider fields to test their applicability and breadth. This has been notably the case with Werner's ideas in their application to complex compounds. Here there has been no such remarkable discovery as that of two years ago regarding the optical isomerism of inorganic compounds, nevertheless there has been an increasing use of these ideas in the explanation of the constitution of compounds which are inexplicable by any of the older theories; as for example Weinland's work on basic salts and that of Rosenheim on the poly-acids of molybdenum, tungsten, etc. Continuing his work on the ferric acetates, where the dominating kation contains three ferric atoms and six acetate groups (hexacetato-triferri base), Weinland has studied ( $Z$. anorg. Chem., 80, 402) the compounds formed by the action of pyridine on a solution of a ferric salt in anhydrous acetic acid. Different compounds are formed according to the proportions used, but the characteristic point is that the ratio of iron to acetate in the kation changes with the entrance of pyridine from $3: 6$ to $2: 3$. A typical formula is $\left(\mathrm{Fe}_{4}\left\{\begin{array}{l}\left(\mathrm{CH}_{3} \mathrm{CO}_{2}\right)_{6} \\ 3 \mathrm{pyr} \\ (\mathrm{OH})_{2}\end{array}\right)^{++++}\right.$, though other kations are formed containing 